\title{
Anabases
}

ANABASES Traditions et réceptions de l'Antiquité

3 | 2006

Varia

\section{Physiologos. Le bestiaire des bestiaires. Texte traduit du grec, introduit et commenté par Arnaud ZUCKER}

\section{Cristina Noacco}

\section{OpenEdition}

Journals

Édition électronique

URL : http://journals.openedition.org/anabases/2624

DOI : 10.4000/anabases. 2624

ISSN : 2256-9421

\section{Éditeur}

E.R.A.S.M.E.

\section{Édition imprimée}

Date de publication : 1 mars 2006

Pagination : 279-281

ISSN : 1774-4296

\section{Référence électronique}

Cristina Noacco, «Physiologos. Le bestiaire des bestiaires. Texte traduit du grec, introduit et commenté par Arnaud zUCKER », Anabases [En ligne], 3 | 2006, mis en ligne le 01 janvier 2012, consulté le 21 septembre 2020. URL : http://journals.openedition.org/anabases/2624 ; DOI : https://doi.org/ $10.4000 /$ anabases. 2624

Ce document a été généré automatiquement le 21 septembre 2020

(c) Anabases 


\title{
Physiologos. Le bestiaire des bestiaires. Texte traduit du grec, introduit et commenté par Arnaud ZUCKER
}

\author{
Cristina Noacco
}

\section{RÉFÉRENCE}

Physiologos. Le bestiaire des bestiaires. Texte traduit du grec, introduit et commenté par Arnaud zUCKER, Grenoble, Éditions Jérôme Millon, 2004, 325 p.

33 euros / ISBN : 2-84137-171-9.

1 Le texte grec du bestiaire chrétien le plus ancien, rédigé très probablement au $\mathrm{II}^{\mathrm{e}}$ siècle en Égypte, fait l'objet, dans cet ouvrage, d'une première traduction intégrale en français moderne, accompagnée d'un riche commentaire.

2 Il s'agit, à proprement parler, d'une série de quatre collections diverses composées à partir d'un modèle littéraire commun et qui ont donné naissance à un genre littéraire dont la popularité s'est répandue jusqu'à la fin du Moyen Âge. Le Physiologos est une œuvre qui se trouve au carrefour de plusieurs traditions: la zoologie grecque, l'ésotérisme égyptien, la mystique juive, l'exégèse alexandrine et la théologie chrétienne du salut.

Le texte de la version grecque du Physiologos présentée par A. Zucker se compose de 64 chapitres, qui présentent cinquante-six animaux, six pierres et deux arbres. Pour les notices concernant la première collection (p.53-257), qui constitue la section la plus ancienne de l'œuvre, ainsi que la plus approfondie d'un point de vue spirituel, il reproduit l'édition Offermans (1966), tandis que pour les notices animalières de la deuxième collection (p.258-293) et de la troisième (p.294-311), il adopte l'édition Sbordone (1936). En revanche, A.Zucker signale qu'il n'a pas pris en compte le quatrième groupe de textes, qui correspond à une réécriture très tardive de la deuxième collection (en appendice dans l'édition Sbordone). 

naturelles» - un prétexte pour l'exposition des vérités morales et théologiques qui fondent la vie du chrétien. Cette notion de conduite morale uniforme à l'enseignement évangélique est rendue par le terme politeutês, initialement lié au domaine politique mais dont le sens de "citoyen du royaume de Dieu » apparaît déjà dans une épître paulinienne (Philippiens, I, 27). A. Zucker signale que l'interprétation spirituelle de la nature des animaux dépasse largement cette première lecture morale: la réalité naturelle (et parfois fabuleuse) de l'animal est évoquée essentiellement pour expliquer le mystère de l'incarnation de Dieu et son plan de salut pour le genre humain. Ainsi, le choix de la nature à décrire se fait-il à rebours, puisqu'il découle de la vérité théologique que l'aspect naturel de l'animal est censé véhiculer.

7 Si la formule «le Physiologue a bien parlé de tel animal » apparaît, de manière récurrente, à la fin des chapitres, c'est que le théologien qui se cache derrière ce nom a pu instaurer une « correspondance exacte de la nature et de l'exégèse : le Physiologue donne lui-même la serrure et la clé de l'image qu'il décrit» (p.22). Une telle interprétation (logos) de la nature (physis) reflète la filiation qu'ont établie, entre le $\mathrm{I}^{\mathrm{er}}$ et le $\mathrm{II}^{\mathrm{e}}$ siècle, Philon, Clément d'Alexandrie et surtout Origène entre les éléments de la Création et les mystères du Créateur, conception qui a abouti à la théorisation des trois sens de l'Écriture alors reconnus : littéral, allégorique et anagogique.

En suivant la structure bipartite du Physiologos, A. Zucker présente, en regard de la traduction française et du texte grec (dont on peut regretter la disposition en bas de page et la présentation en corps typographique réduit), un riche commentaire, permettant d'éclairer les enjeux théologiques du texte, la tradition zoologique antérieure et l'évolution des figures animales chez les principaux traducteurs et héritiers médiévaux du Physiologos. Par exemple, le long commentaire qui suit le chapitre 7 consacré à "L'oiseau Phénix» (p. 85-88) comporte, dans l'ordre, un développement sur la présence du symbole dans les différentes traditions mythologiques de l'Antiquité, une interrogation sur la valeur positive ou négative que les auteurs gréco-latins et médiévaux lui ont attribuée, une explication de la portée allégorique de l'oiseau et de la portée symbolique - morale et spirituelle - des composantes de l'histoire, ainsi que la citation des exégètes chrétiens majeurs qui se sont inspirés de ce texte.

9 La traduction est sobre et élégante. Elle répond à un premier souci de fidélité à la lettre, notamment lorsque cette dernière insiste sur l'ambiguïté d'un terme (par ex., au chap. 34, consacré à "L'arbre péridexion ", l'auteur a choisi de transposer directement dans la traduction cet adjectif, afin d'en garder la double signification d' " ambidextre " et de «favorable»). D'autre part, dans un souci de clarté, A.Zucker prend soin 
d'interpréter le texte (par exemple quand il traduit le terme psychê par « vie » (chap. 7, $\S 1,1.2$ ), plutôt que par «âme»), sans toutefois le trahir, le terme retenu étant le plus souvent suggéré par le contexte.

10 Les analyses sont fines et précises, toujours fidèles au sens étymologique et/ou contextuel de la narration et témoignent des vastes connaissances de l'auteur. Dans les notes qui apparaissent à la fin du volume, A. Zucker donne les références des citations bibliques contenues dans le Physiologos, ainsi que des renseignements rigoureux concernant le sens littéral ou figuré, non retenu, de quelques termes.

11 Cet ouvrage très attendu rend enfin accessible au public francophone un texte fondamental pour la compréhension de la translatio studii de l'Antiquité au Moyen Âge, et il répond à la double et délicate exigence qui résonnait dans l'adage latin placere et docere: celle de captiver, par une traduction fluide et savoureuse, le lecteur le moins averti et celle d'instruire, par des références méta-textuelles riches et précises, le public le plus exigeant, celui des spécialistes.

\section{AUTEUR}

\section{CRISTINA NOACCO}

Université de Toulouse II-Le Mirail

cnoacco@yahoo.fr 